\title{
Restaurando el diálogo de las manos a través del arte guiñol
}

\author{
Restoring the Dialogue of Hands Through Puppet Theatre
}

\author{
Sergio Arturo Montero Alarcón \\ Escuela Nacional de Conservación, Restauración y Museografía (ENCRyM), \\ Instituto Nacional de Antropología e Historia (INAH), México \\ smontero37@yahoo.com.mx
}

\section{Verónica Chacón Roa}

Sistema de Transporte Colectivo Metro (STC-Metro), México veroxchacon@yahoo.com.mx

\section{Resumen}

El presente ESCAPARATE describe los antecedentes, génesis y desarrollo del Proyecto de Restauración de la Colección de la Época de Oro del Teatro Guiñol del Instituto Nacional de Bellas Artes (INBA), iniciativa de la Escuela Nacional de Conservación, Restauración y Museografía, Instituto Nacional de Antropología e Historia (ENCRYM-INAH) en colaboración con el Consejo Estatal para la Cultura y las Artes de Puebla CECAP, el INBA y el Consejo Nacional para la Cultura y las Artes, (Conaculta, México) durante el cual se realizó la documentación, investigación e intervención de más de 400 marionetas elaboradas entre 1933 y 1965 en papel, madera, textiles, fibras animales, la mayoría de confección moderna y, en algunos casos, con policromía de naturaleza industrial. Se reseñan tanto la fase de documentación activa, que llevó a la conformación de una base de datos multificha, como los diversos tratamientos que permitieron la recuperación de los valores históricos, estéticos y funcionales de los guiñoles.

\section{Palabras clave}

marioneta; teatro guiñol; restauración; cartonería; indumentaria

\section{Abstract}

This GALLERY describes the background, creation and development of the Proyecto de Restauración de la Colección de la Época de Oro del Teatro Guiñol del Instituto Nacional de Bellas Artes (INBA) (Restoration Project of the Golden Age Puppet Theatre Collection of the National Institute of Fine Arts), an initiative of Escuela Nacional de Conservación, Restauración y Museografía, Instituto Nacional de Antropología e Historia (ENCRyM-INAH, National School of Conservation, Restoration and Museum Studies, National Institute of Anthropology and History) in collaboration with Consejo Estatal de Cultura y las Artes de Puebla (Culture and Arts, Puebla State Council), Puebla INBA and Consejo Nacional de la Cultura y las Artes (Conaculta, Culture and Arts National Council). More than 400 puppets were documented, studied and intervened during this project. These 
puppets, elaborated between 1933 and 1965 were made of paper, wood, textile and animal fibres; the majority manufactured in a modern way and some with industrial polychrome. The article presents the phase of active documentation that led to the setting up of a multirecord database and it describes the various treatments that allowed for the recovery of historic, aesthetic, and functional values of the theatre puppets.

\section{Key words}

marionettes; puppet theatre; restoration; papier mâché craft; clothing

FIGURA 1. Procesos de documentación de marionetas (Fotografía: Proyecto de Restauración de la Colección de la Época de Oro de Teatro Guiñol de Bellas Artes, 2014; cortesía: ENCRYM-INAH).



tes (Conaculta) y el INAH, a través de la ENCRyM (todos, en México). Tal y como su nombre sugiere, el proyecto se enfocó en la restauración de una colección de marionetas pertenecientes al esplendor del arte guiñol del INBA que, por acuerdo de comodato, hoy están bajo custodia del consejo estatal referido.

Ésta no sería la primera vez que Montero Alarcón conjuntara sus extensas trayectorias como restaurador y como titiritero (Garduño Ortega 2010:39-44). Las intervenciones de elementos protagónicos del arte guiñol de nuestro país datadas en 1983, 1989-1990, 1995 y 2007-2009 han contado con su experimentada dirección, por lo que cuenta en su haber con las restauraciones de la Colección Rosete Aranda del Centro de Teatro Infantil (CTI) del INBA y la Colección de Títeres del Museo Rafael Coronel (MRC, Zacatecas, México), más la de un lote adicional, de más de 300 elementos, del acervo del INBA (Montero Alarcón 1995:4-5; Garduño Ortega 2010:39-44). No obstante, el proyecto de 2014 al que se dedica este ESCAPARATE significó nuevos retos, no sólo por tratarse de una serie de más de 535 marionetas — de las que se restauraron 400 - sino también por su diversidad temporal y material: los elementos se produjeron entre 1933 y 1965 en papel, madera, textiles, fibras animales, la mayoría de confección moderna y, en algunos casos, con policromía de naturaleza industrial; esto es, una variopinta muestra del arte de la producción del collage, de cuyo contexto de fabricación y uso vale la pena hacer una síntesis que explicite los valores culturales adscritos a esta peculiar manifestación de nuestro patrimonio (Figura 1). 


\section{Marionetas educativas}

El origen del guiñol es legendario: aunque se cuenta con evidencia de la existencia de espectáculos de títeres en el Oriente desde hace 3000 años, la creación del teatro guiñol en Europa se le atribuye a Monsieur Guignol de Laurent Mourguet, un dentista francés originario de Lyon que en el siglo XIX hacía representaciones con muñecos de guante detrás de su gabinete con el propósito de entretener a sus pacientes (Cerdá y Cerdá 1966:54; Iglesias Cabrera y Murray Prisant 1995:82). Aunque México no posee una tradición titiritera comparable con la de Asia o Europa, ${ }^{1}$ el siglo XIX es más rico en referencias de titiriteros nacionales, entre los cuales destaca la conocida compañía de Rosete Aranda, que en 1835 inició una actividad cuya vida se extendió hasta más de un siglo después (Montero Alarcón 1995:5).

En este sentido, es notable el vínculo entre los capítulos fundacionales de la historia del guiñol en México durante el siglo xx y el desarrollo institucional pedagógico y artístico de los gobiernos posrevolucionarios: efectivamente, entre 1931 y 1934 el secretario de Educación Pública Narciso Bassols dirigió una campaña que se denominó Misiones Culturales, cuyo objeto -en consonancia con la ideología de educación socialista de la época- fue asistir a maestros rurales en tareas de culturización, alfabetización y

\footnotetext{
${ }^{1}$ Aunque se carece de evidencias informativas y materiales, es probable que en nuestro país haya existido teatro de títeres tanto en la época prehispánica como en el virreinato (Montero 1995:4).
}

salubridad para infantes y adultos, en colaboración con artistas (INBA 2010:21).

Entre estos últimos cabe mencionar un grupo de figuras y actividades que definirían el devenir del arte guiñol mexicano entre los años 1930 y 1960, es decir, su época de oro (INBA 2010:2). Destaca, en primer lugar, el polifacético escritor y artista Germán List Arzubide, quien, tras descubrir el teatro guiñol en su larga estancia de autoexilio en la entonces Unión Soviética, sería no sólo el responsable, con los auspicios de Bassols, de configurar los elementos indispensables para representar obras de títeres a lo ancho y largo de nuestro país, sino también autor de la comedia $\mathrm{CO}^{-}$ mino vence al Diablo, paradigmática de la cúspide del arte guiñol mexicano (UNAM 1997:VIII; List Arzubide 1997). Asimismo, vale mencionar al escultor Germán Cueto y a su esposa, la pintora y grabadora Lola Cueto, sobresalientes artistas mexicanos, que trabaron amistad con List Arzubide en una escala en París durante su regreso a México, y posteriormente se encargaron del diseño de muchos de los escenarios e indumentarias de personajes que representarían obras de cuentos y de bailes conocidos tanto en México como en el resto del mundo (UNAM 1997:VIII; List Arzubide 1997). A ellos habría que sumar el fortuito encuentro de List Arzubide, Germán Cueto y Lola Cueto con la grabadora rusa Angelina Beloff, cuyo conocimiento del teatro guiñol ayudó a despejar dudas sobre el espectáculo y a consolidar el ánimo del proyecto guiñol en el inicio de ese periodo dorado (List Arzubide 1997). A este grupo, ya en México, se unirían otros artis- tas de gran prestigio, como el grabador Leopoldo Méndez y su hermano Teodoro, autor del primer teatrino; Ramón y Dolores, (Loló); Alva de la Canal; Helena Huerta, Julio CasteIlanos y el genio Silvestre Revueltas, quien musicalizaría algunas de las obras (UNAM 1997:VIII; List Arzubide 1997).

Con este trasfondo histórico de gran relevancia se conformó, con indudables cualidades estéticas involucradas en su confección, la colección de títeres del INBA —en manos de grupos de titiriteros adscritos al teatro guiñol del instituto, tales como "El Nahual", "Rin-Rin", "Periquito", "Chapulín"— sirvió para la puesta en escena de múltiples obras de teatro que fueron pilares de programas de educación y cultura desde la década de 1930 hasta la de 1960 (Miranda Silva 2014). Integrada, como hemos dicho, por más de cinco centenares de marionetas, es un conjunto patrimonial único que, desafortunadamente, se encuentra alterado tanto por factores derivados de su funcionalidad como por el natural paso del tiempo y diversas formas de almacenaje, condición que motivó su traslado a la ENCRYM-INAH para su intervención en materia de restauración (Giorguli Chávez, Montero Alarcón, Chacón Roa et al. 2014:4).

\section{Una intervención integral}

Las labores de restauración de la Colección de la Época de Oro del Teatro Guiñol de Bellas Artes — valga decir, del diálogo con las manos- se concibieron de manera integral desde su planeación y las ejecutó el equipo especialmente conformado para el desarrollo de 


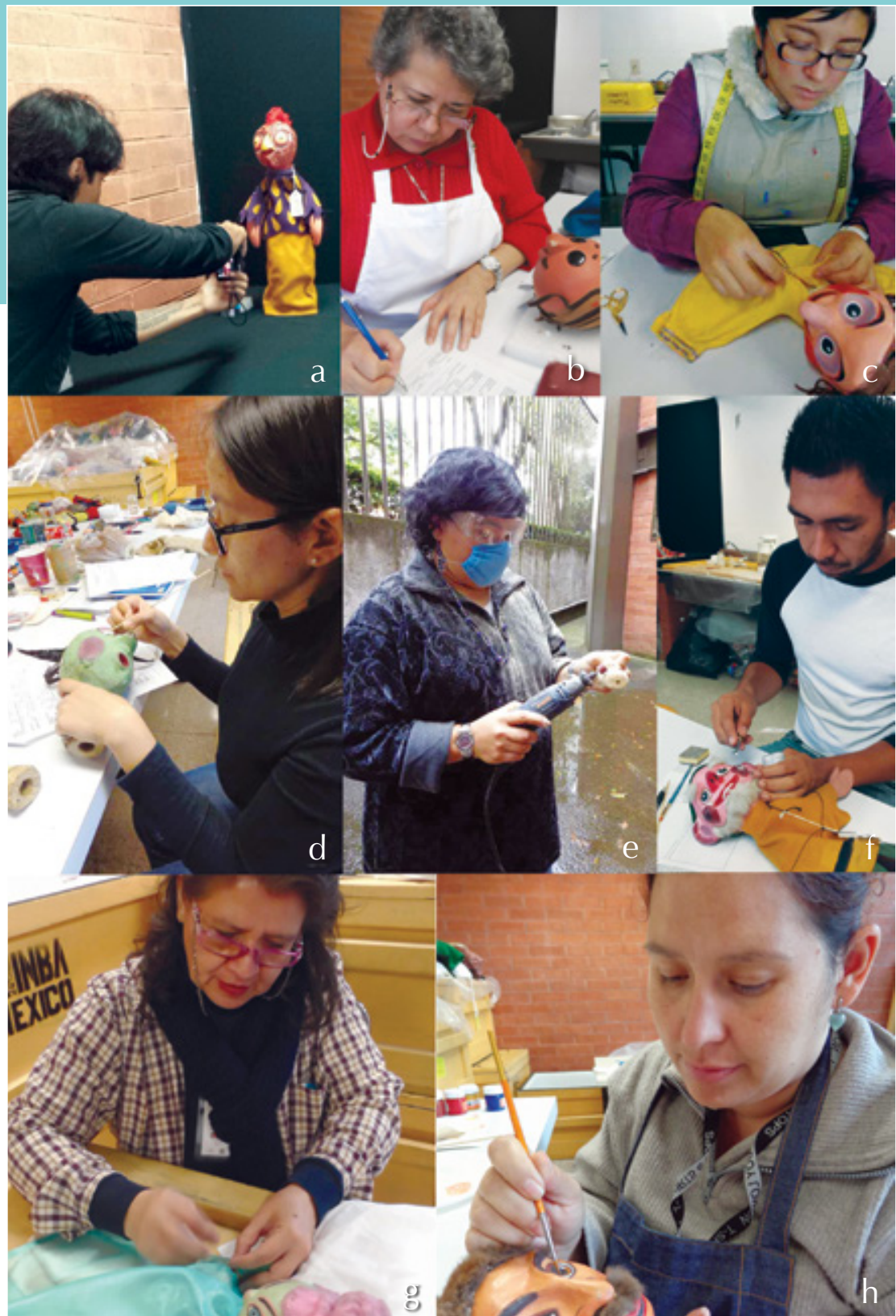

este proyecto ${ }^{2}$ (Figura 2) constituido por tres fases de trabajo, cada una con innovaciones, de las que se da cuenta a continuación.

\footnotetext{
2 Participaron en este proyecto: la licenciada Liliana Giorguli Chávez y el profesor Sergio Arturo Montero Alarcón (directores del proyecto); los restauradores Verónica Chacón Roa (coordinadora residente), Saydé Sortibrán Cárdenas, Luz Elena Valencia Escárcega, Ana Julia Poncelis Gutiérrez, Araceli Zah-Nicté Ocampo Plasencia, Karla Elena Velázquez Montaño y Juan Antonio Segovia Trujillo, así como la auxiliar en restauración Elia Esther Estrello Bernal.
}

\section{Documentación activa}

La colección que aquí nos ocupa se entregó a la ENCRyM-INAH en siete contenedores cerrados, acompañada por un listado de obra que reflejaba el número de inventario, las dimensiones de cada pieza y una breve descripción de ellas, en virtud de lo cual se decidió iniciar con una documentación sistemática. Si bien los métodos empleados para este proceso fueron convencionales: observación, medición y fotografía de cada uno de los elementos, la cantidad de
FIGURA 2. Procesos de restauración de las marionetas: a. Registro fotográfico; b. Documentación; c. Desarmado; d. Limpieza; e. Reposición de elementos; f. Resane de faltantes; g. Armado h. Reintegración cromática (Fotografía: Proyecto de Restauración de la Colección de la Época de Oro del Teatro Guiñol de Bellas Artes, 2014; cortesía: ENCRYM-INAH).
FIGURA 3. Diseño de la ficha clínica en base de datos (File-Maker Pro@) (Fotografía: Proyecto de Restauración de la Colección de la Época de Oro del Teatro Guiñol de Bellas Artes, 2014; cortesía: ENCRyM-INAH).

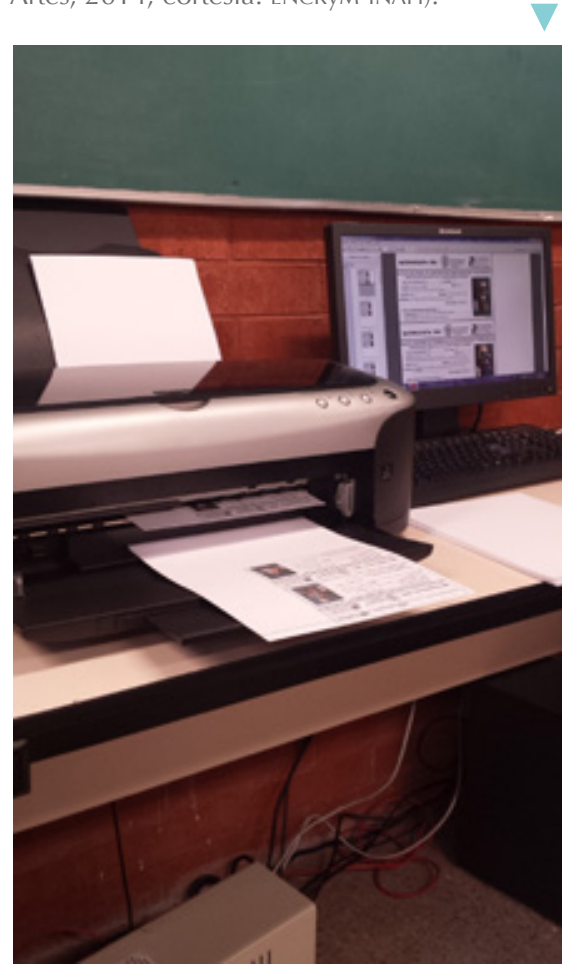

objetos involucrados requirió que se integrara una innovación tecnológica, consistente en el diseño de una base de datos específica con una plataforma de software FileMaker 11 Advance, la cual se fundó en fichas clínicas empleadas en colecciones análogas que, en el marco del proyecto actual, se renovaron según las necesidades propias de registro y gestión de la colección (Figura 3).

El resultado fue una multificha electrónica analítica con celdas de información descriptiva y una clasificación de los elementos dividida 


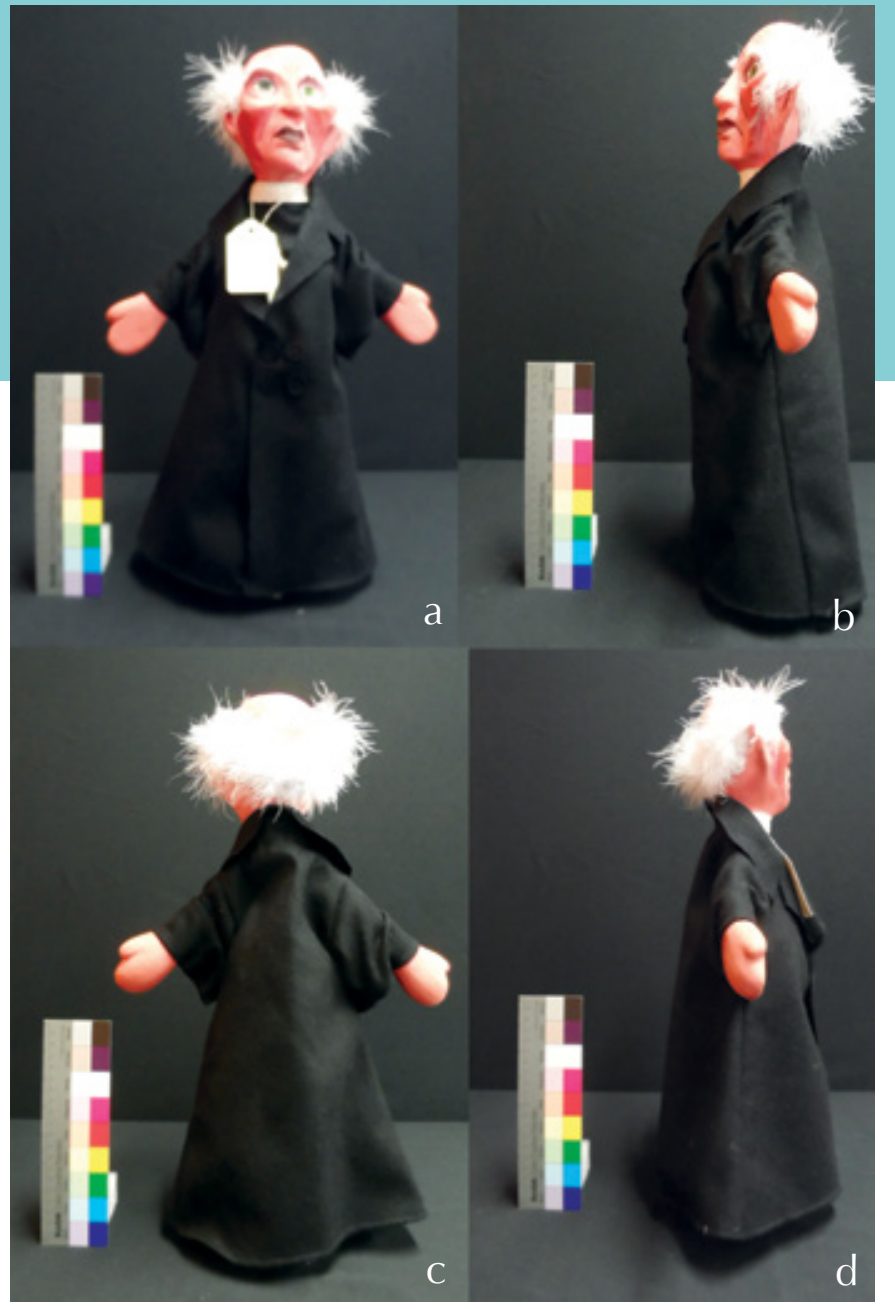

FIGURA 4. Vistas fotográficas del guiñol Inv. 58186 en cuatro ángulos, optimizadas en Photoshop CS3 (Fotografía: Proyecto de Restauración la Colección de la Época de Oro del Teatro Guiñol de Bellas Artes, 2014; cortesía: ENCRyM-INAH).

FIGURA 5. Fichas de levantamiento de información en base de datos. a. Estado de conservación; b. Procesos de restauración (Fotografías: Proyecto de Restauración de la Colección de la Época de Oro del Teatro Guiñol de Bellas Artes, 2014; cortesía: ENCRyM-INAH).

$\mathrm{a}$

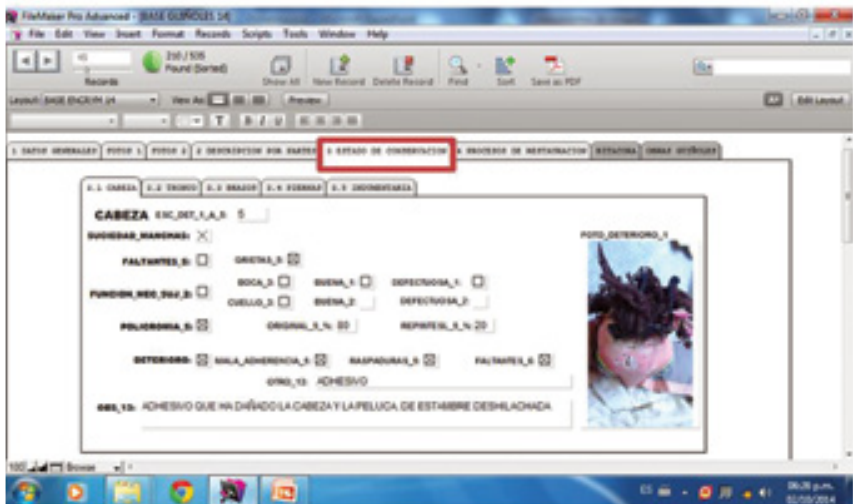

b

en cuatro categorías: de títeres de crucetas y cuerda, varillas, guiñol y mixtos. Como parte del registro, cada uno de los elementos se fotografió en cuatro ángulos con una cámara Sony Cyber-Shot DSC-H90 de 16.1 megapixeles, la que se calibró a una calidad de 4 megapixeles y en un tamaño de 14.10 X 18.81, lo que dio como resultado imágenes de 350 DPI (Figura 4). Una selección de éstas se optimizó en una plataforma de manejo de gráficos (Photoshop CS3) para reducir su resolución a 96 DPI con el fin de integrarlas a la plataforma electrónica. A ello se sumaron datos esenciales de manufactura y un levantamiento del estado de conservación, con imágenes de detalle pertinentes (Figura 5).

Un aspecto digno de subrayar es que la base de datos se configuró como un sistema activo - de ahí el nombre de documentación activa - para registrar las intervenciones realizadas con imágenes tanto de proceso como de término de cada intervención, de modo que su empleo fue útil como un instrumento no solamente de documentación sino también de control de avance y desempeño de los recursos humanos.

Al término del proceso de documentación la base de datos alcanzó un promedio de 11500 imágenes integradas en fichas individuales: un universo manejable en una minilap con procesador Atom y de sólo $1 \mathrm{~Gb}$ en RAM. La información, amén de que puede filtrarse para generar el control total de la colección, ofrece estadísticas de lugar de embalaje, de manufactura, de estado de conservación al llegar a la ENCRyM y de los procesos de restauración que se realizaron. La base de datos puede, asimismo, transformarse en un archivo ejecutable y visualizarse en cualquier sistema operativo y configurarse para mostrarse en internet; esta información sirve como un complemento indispensable a recientes publicaciones multimedia de catálogo sobre la colección (Giménez Cacho y Miranda Silva 2010). 
FIGURA 6. Materiales de factura de las marionetas del Proyecto de Restauración de la Colección de la Época de Oro del Teatro Guiñol de Bellas Artes (Esquema: Provecto de Restauración de la Colección de la Época de Oro del Teatro Guiño de Bellas Artes, 2014; digitalización: Jorge Alejandro Bautista Ramírez cortesía: ENCRyM-INAH).
FIGURA 7. Ilustraciones de técnicas de manufactura de las marionetas del Proyecto de Restauración de la Colección de la Época de Oro del Teatro Guiñol de Bellas Artes, 2014. a. Cabeza de cartonería (Inv. 57732); b. Cabeza de madera ligera (Inv. 58190); c. Cabeza de cartonería con aditamentos de piel y textiles (Inv. 58126); d. Manos de cartonería (Inv. 58005); e. Manos de madera ligera (Inv. 57861); f. Manos de textil relleno (Inv. 58016); g. Indumentaria de mujer (Inv. 54313); h. Indumentaria de niño (Inv. 57736); i. Indumentaria del señor Guiñol (Inv. 58016) (Fotografía: Proyecto de Restauración de la Colección de la Época de Oro del Teatro Guiñol de Bellas Artes, 2014; cortesía: ENCRYM-INAH).

\section{Investigación dinámica}

La investigación sobre la colección que aquí comentamos derivó en tres líneas principales: técnica de manufactura, historicidad y funcionalidad.

En el primer rubro inicialmente se realizaron observaciones particulares en las marionetas para identificar sus materiales de factura, entre los cuales se observaron las siguientes variables (Figuras 6 y 7 ).

Cabe señalar que la presencia de restos de periódico legible como parte del relleno de las piezas ofreció una evidencia de su datación y contexto histórico. Por ejemplo, en el relleno de las patas del guiñol 57927, que representa a un zorro, se hallaron fragmentos de periódicos fechados para 1946 que mostraban anuncios de comercios de la época; este material, con valor de documento, se fotografió y, al terminar los procesos de restauración, se devolvió a su lugar de procedencia (Figura 8).

Asimismo, es de notar la gran diversidad de las indumentarias, que presentaron desde diseños sencillos tipo túnica hasta muy elaborados, con sombreros, abrigos, vestidos de novia, o bien de estilos tradicionales de México y del mundo, incluidos trajes típicos para bai-
Materiales de factura de las marionetas del Proyecto de Restauración de la Colección de la Época de Oro del Teatro Guiñol de Bellas Artes

\begin{tabular}{|c|c|c|}
\hline \multirow{3}{*}{ Cabezas } & Relleno & Papel periódico \\
\hline & Estructura & $\begin{array}{c}\text { Cartonería } \\
\text { Madera ligera }\end{array}$ \\
\hline & Decoración & $\begin{array}{c}\text { Estambre } \\
\text { Textiles } \\
\text { Pieles de animales: conejo, chinchilla, gato (?) } \\
\text { Botones }\end{array}$ \\
\hline Manos & & $\begin{array}{l}\text { Cartonería } \\
\text { Madera (colorín) } \\
\text { Textil }\end{array}$ \\
\hline Cuerpos & & les: guante de sostén e indumentaria \\
\hline
\end{tabular}
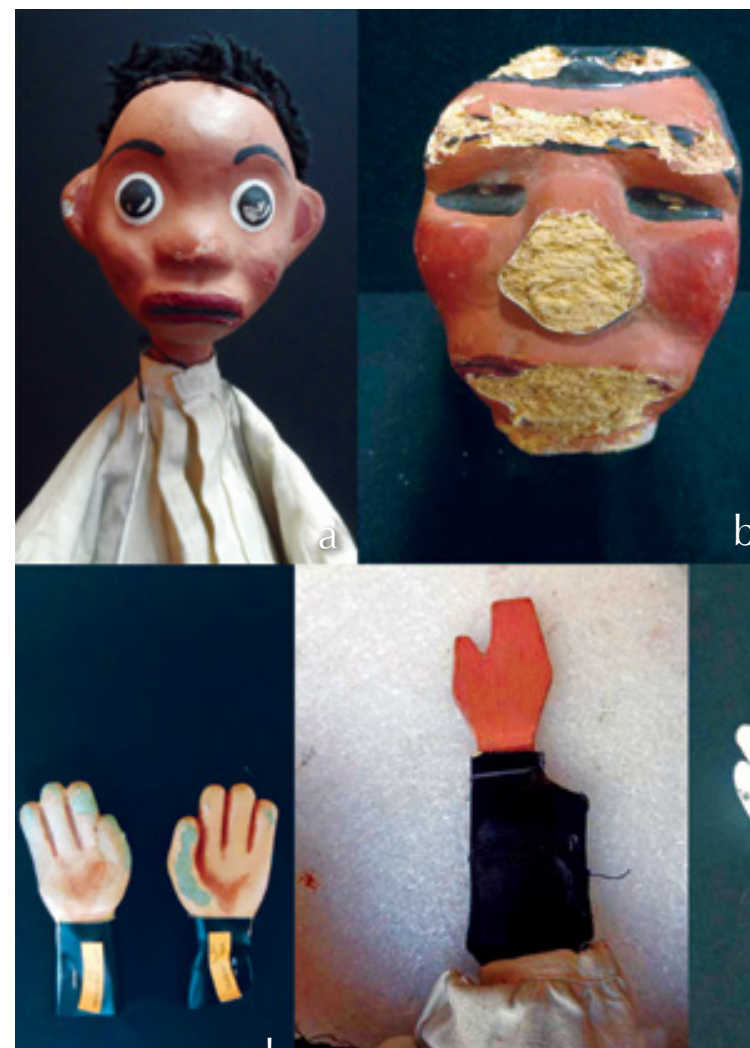

b
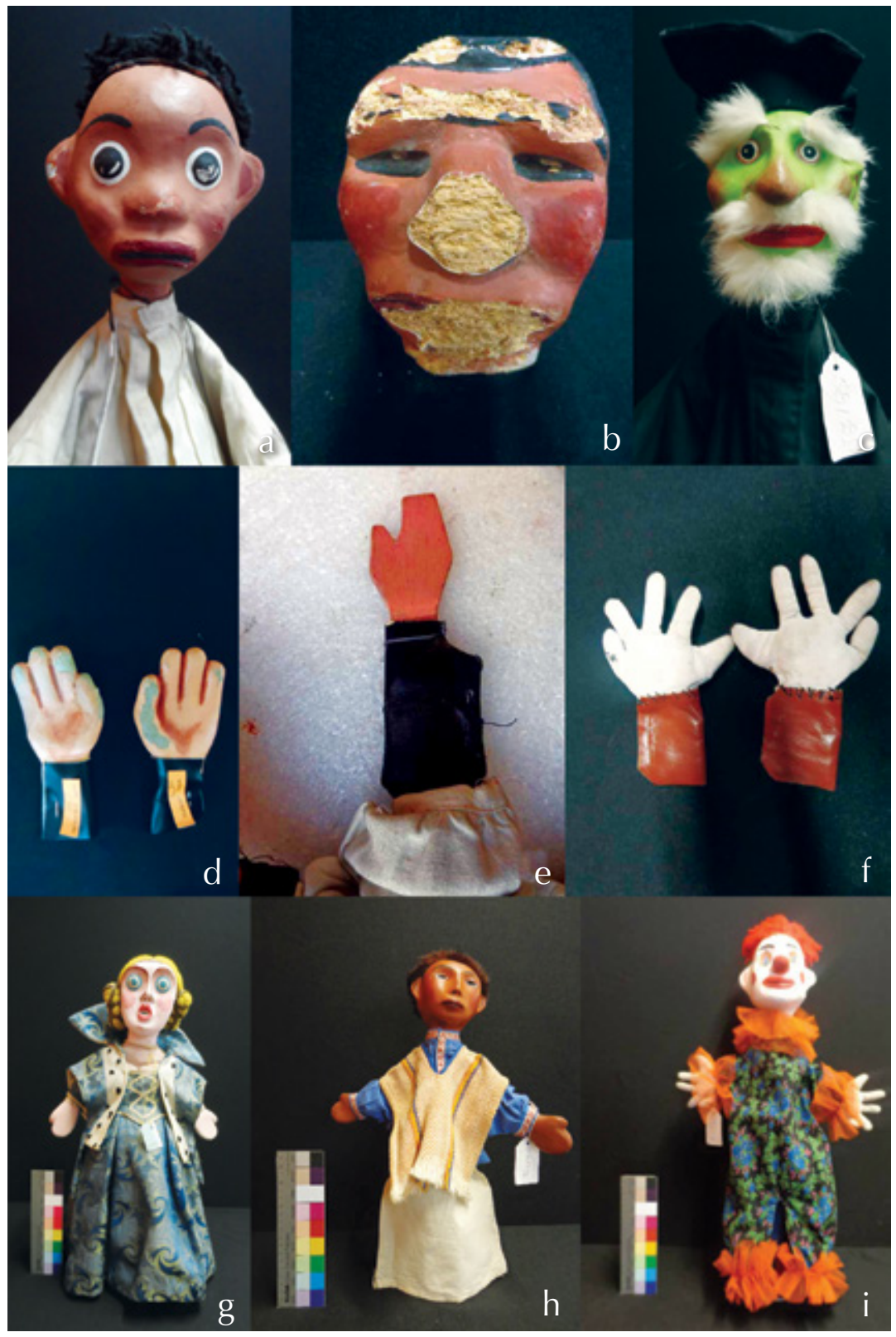


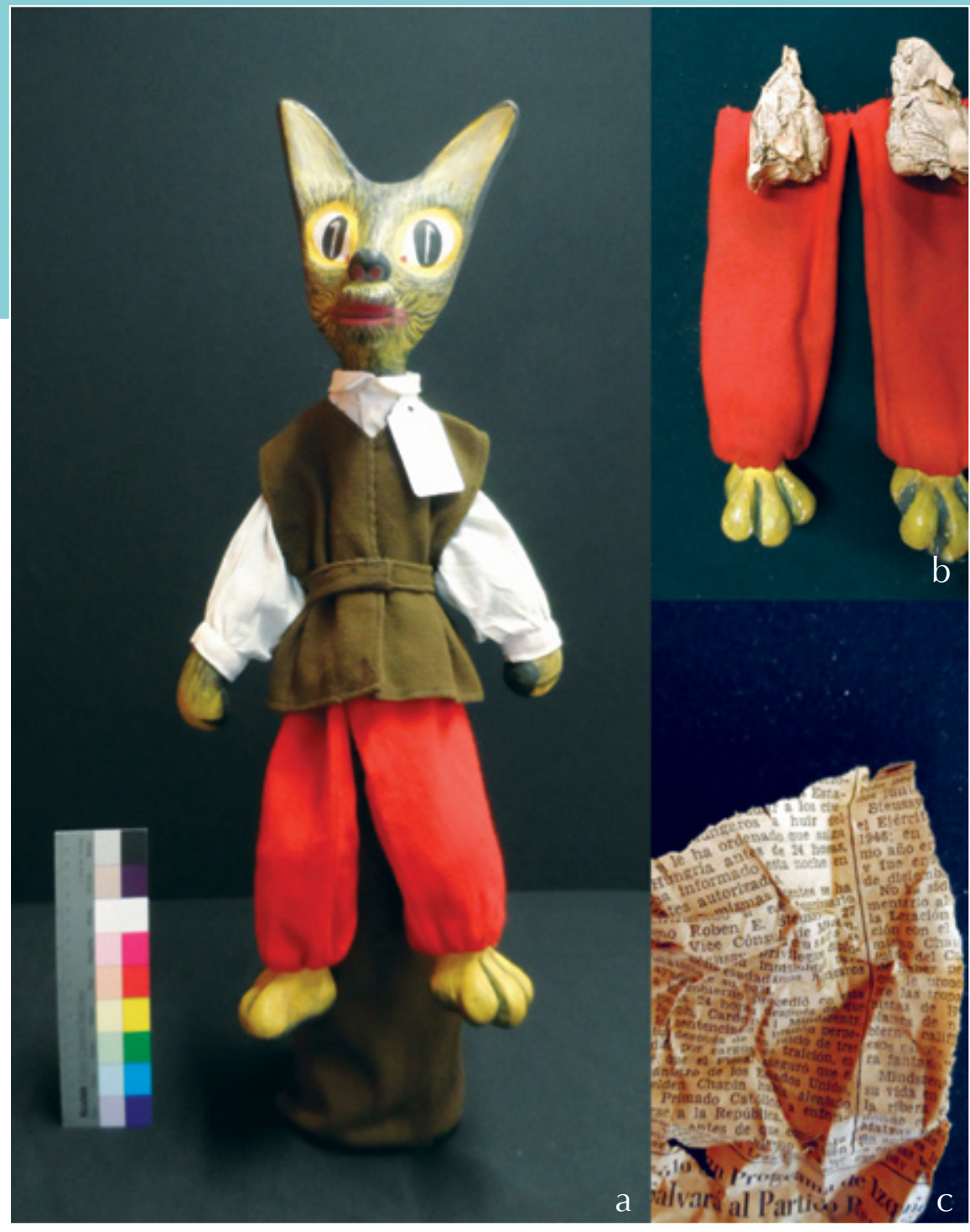

les como el "Son jarocho" de Veracruz, "Las tehuanas" de Oaxaca o la "Danza de las lagarteranas" de Toledo, España (Figura 9). Marionetas muy sofisticadas, como las diseñadas por Lola Cueto, contaban con decoración de flores manufacturadas de tela y papel, lo que exigió hacer una consultoría temporal para su tratamiento. ${ }^{3}$

Aspectos sobre la producción de los atuendos de algunas marionetas se documentaron en la base de

\footnotetext{
${ }^{3}$ Para ello se contó con la participación de Adriana Peyron Pucheu y la restauradora Adriana Sanroman Peyron, herederas de la Fábrica de Flores Artificiales Pucheu, en la colonia Obrera de la ciudad de México.
}

datos referida gracias a recientes trabajos sobre la colección (Giménez Cacho y Miranda Silva 2010), lo que permitió profundizar no sólo en los procesos de su creación sino también en el significado de piezas particulares, como las que elaboró Angelina Beloff para la obra El viejo, el gato, el gallo y la zorra de 1933, Lola Cueto para Blanca Nieves y los siete enanos en 1945 y Roberto Lago para El señor Guignol alfabetizador de la misma década (Giménez Cacho y Miranda Silva 2010:57).

Tanto en el rubro de la manufactura como en el de la historicidad, los restauradores que tomamos parte en el proyecto tuvimos la oportunidad de dialogar con protagonistas y estu-
FIGURA 8. Presencia de restos de periódico como relleno en guiñol Inv. 57927, en el cual aparece la fecha de 1946, misma que sirve de datación (Fotografía: Proyecto de Restauración de la Colección de la Época de Oro del Teatro Guiñol de Bellas Artes, 2014; cortesía: ENCRYM-INAH).

diosos del teatro guiñol en México, como la maestra Marisa Giménez Cacho, promotora, por parte del INBA, del rescate de las series de marionetas tratadas por el profesor Montero Alarcón, subdirectora del Programa de Teatro para Niños y Jóvenes de esa institución y autora del catálogo más completo de la colección a la que aquí nos referimos (Giménez Cacho y Miranda Silva 2010); su coautora, la maestra Francisca Miranda Silva, investigadora del teatro guiñol de Bellas Artes, y Raquel Bárcena, pedagoga y primera directora del Museo Nacional del Títere (Munati, Huamantla, Tlaxcala, México). Estas comunicaciones - a la par de lo que hoy se plantea en el arte contemporáneo, con la entrevista a artistas vivos (Mata Delgado y Landa Elorduy 2011:74-79)_ permitieron conocer detalles sobre el carácter funcional de las piezas: su instancia "performativa" (Garduño Ortega 2010:41), que, junto con consideraciones sobre su manufactura e historicidad, constituyeron los ejes fundamentales para la toma de decisiones en materia de intervenciones de restauración.

\section{Intervención específica}

Ante la diversidad de manufacturas, historicidades y funcionalidades de las marionetas, no es de extrañar que presentaran alteraciones específicas que demandaron, a su vez, intervenciones muy particulares. Es, por lo tanto, difícil resumir todas las intervenciones realizadas, por lo que aquí únicamente nos referiremos a las generalidades de los casos más representativos de las 400 marionetas intervenidas. 


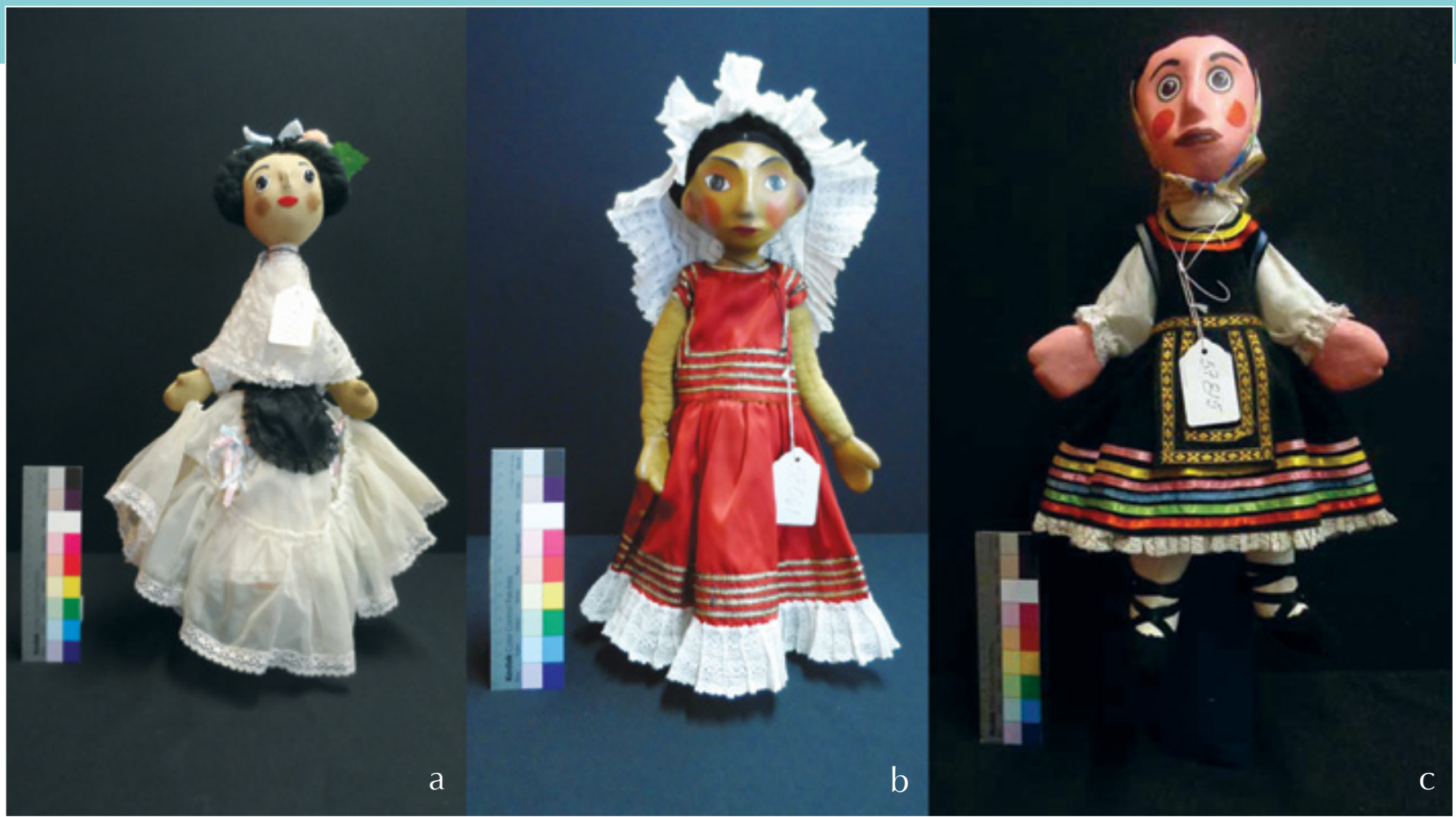

Una vez concluida la documentación escrita y gráfica de cada una de las piezas, por lo general se desarmaron con el fin de comprender su confección y documentar sus partes. A ello siguió un proceso de limpieza, que consistió en un simple aspirado y lavado con agua/canasol.

El cartón se restauró restableciendo las bases de su factura: la estructura se reforzó mediante capas de papel Kraft cortadas en el sentido de la fibra, para generar puntos de unión, adheridas con engrudo que, una vez seco, se lijó para montar la capa subsecuente; sobre ésta se aplicó una base de preparación sintética de marca comercial entintable que serviría para recibir la policromía a base de acrílicos, material seleccionado porque ya se había empleado en las marionetas durante una intervención anterior. Secto- res con técnica de cartón que habían perdido forma por presión se restablecieron en el plano mediante humectación y compresión hasta el punto de establecer su unidad visual. También se hicieron resanes, los cuales se reintegraron cromáticamente con los materiales ya descritos.

Por lo general, la indumentaria se sometió a procesos de limpieza húmeda con agua/canasol o con gasolina blanca, con secados y planchados subsecuentes. Los huecos pequeños se restauraron con puntadas de hilo y, en algunos casos, se buscaron dobleces que permitieran extraer parches de la misma tela. Ciertas piezas de indumentaria, muy afectadas por ataque de insectos $y / 0$ roedores, tuvieron que restituirse por completo con nuevos atuendos, para lo cual se tomó el molde de la original y se utilizó un textil análogo.
Los cambios en varias de las piezas fueron notables, ya que se preservó su materialidad, activando los valores históricos, estéticos y funcionales que los significan como patrimonio (Figura 10).

Una vez que se rearmaron las marionetas, se les proveyó de un empaque protector de bolsas de Tyvek hechas a la medida, las cuales cuentan con cordón y remates que permiten acceso a las piezas según las necesidades. En los cuellos de aquéllas se colocaron "ahorcadores" de Tyvek rematados con Velcro para que los guiñoles no se deslizaran hacia abajo, lo cual permite, si su destino es ser almacenados, que se cuelguen sin lastimar ninguno de sus elementos. El empaque protector, en cuyo interior se depositó sílica gel para el control de humedad, cuenta con una ventana translúcida que 

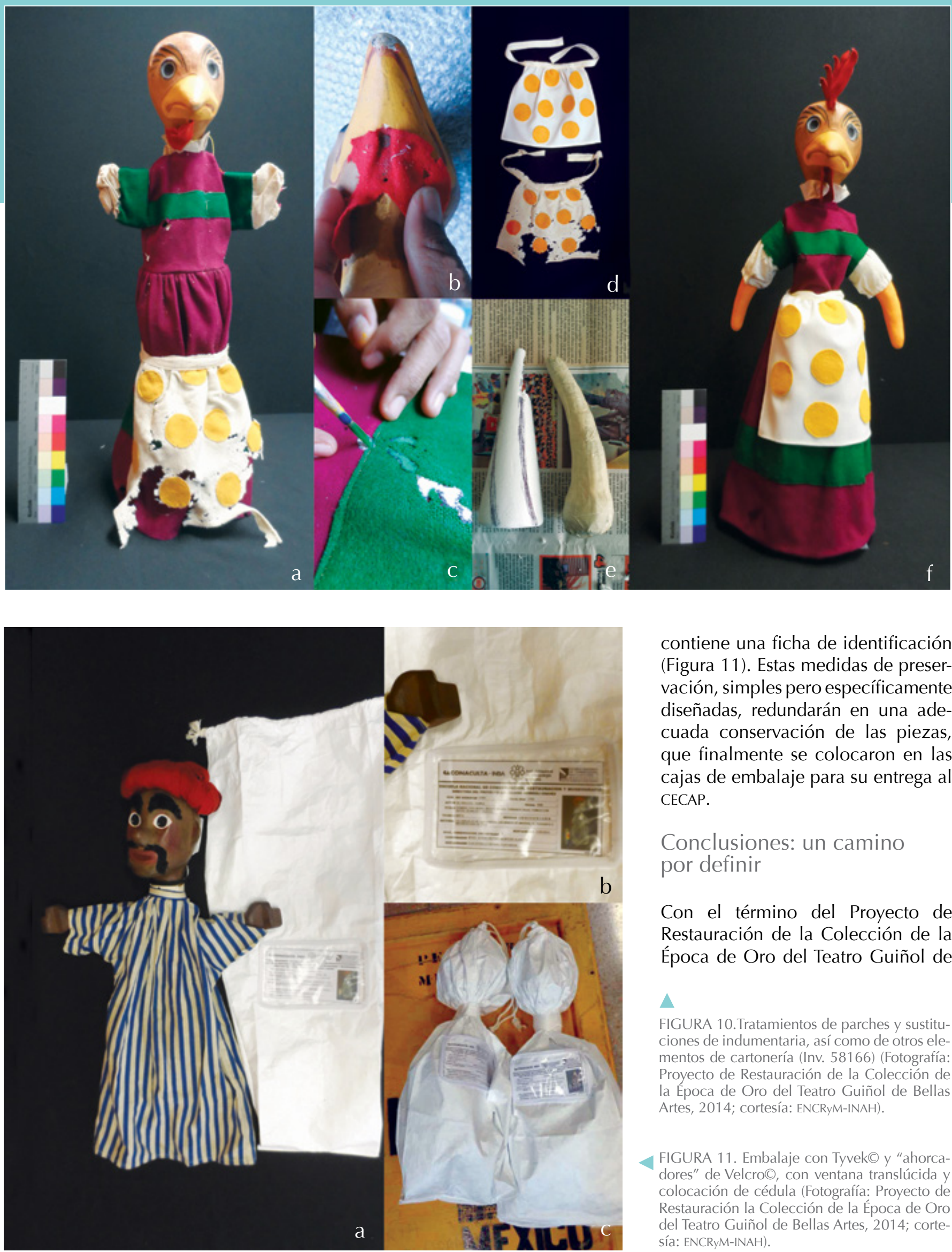

contiene una ficha de identificación (Figura 11). Estas medidas de preservación, simples pero específicamente diseñadas, redundarán en una adecuada conservación de las piezas, que finalmente se colocaron en las cajas de embalaje para su entrega al CECAP.

Conclusiones: un camino por definir

Con el término del Proyecto de Restauración de la Colección de la Época de Oro del Teatro Guiñol de

$\triangle$

FIGURA 10.Tratamientos de parches y sustituciones de indumentaria, así como de otros elementos de cartonería (Inv. 58166) (Fotografía: Proyecto de Restauración de la Colección de la Epoca de Oro del Teatro Guiñol de Bellas Artes, 2014; cortesía: ENCRyM-INAH).

4 FIGURA 11. Embalaje con Tyvek@ y "ahorcadores" de Velcro@, con ventana translúcida y colocación de cédula (Fotografía: Proyecto de Restauración la Colección de la Época de Oro del Teatro Guiñol de Bellas Artes, 2014; cortesía: ENCRyM-INAH). 
FIGURA 12. Fotografías de antes, durante y después de proceso de restauración, que incluye intervenciones en cartonería en la cabeza de la marioneta (Fotografía: Proyecto de Restauración de la Colección de la Epoca de Oro del Teatro Guiñol de Bellas Artes, 2014; cortesía: ENCRyM-INAH).

Bellas Artes se ha cumplido cabalmente con la recuperación de los valores históricos, estéticos y funcionales de una de las series de guiñoles más significativas del patrimonio cultural mexicano (Figura 12), la cual plantea interrogantes, y posibilidades, sobre su futuro: existe, sin duda, el anhelo de volver a contar con su "performatividad" y ver las figuras nuevamente en acción en un escenario con los guiones y musicalizaciones que daban cuerpo al diálogo con las manos de notables artistas creadores, titiriteros y público. Es deseable, y muy tentador, reactivar su doble papel didáctico y lúdico que le dio origen con la propuesta educativa y cuya interlocución hoy es tan necesaria. A la par, existen otras posibilidades de exhibición: por medio de recreaciones museográficas y, por supuesto, a través de los medios digitales que actualmente ofrecen las plataformas electrónicas de difusión mundial. Lo cierto es que también sería deseable que esta nueva forma de poner en acción el guiñol contemplara su segunda vida: la de corresponder a este proyecto y a las enseñanzas que durante su desarrollo se han permitido sustraer, ya sea por contacto con los guiñoles, o bien con quienes saben de sus movimientos escénicos y su historia. Así será posible que la restauración transcurra desde las bambalinas hasta la escena.

\section{Agradecimientos}

Agradecemos a todas las instituciones involucradas en este proyecto, así como a los diversos profesionales que nos ayudaron a profundizar en el conocimiento del teatro guiñol mexicano.

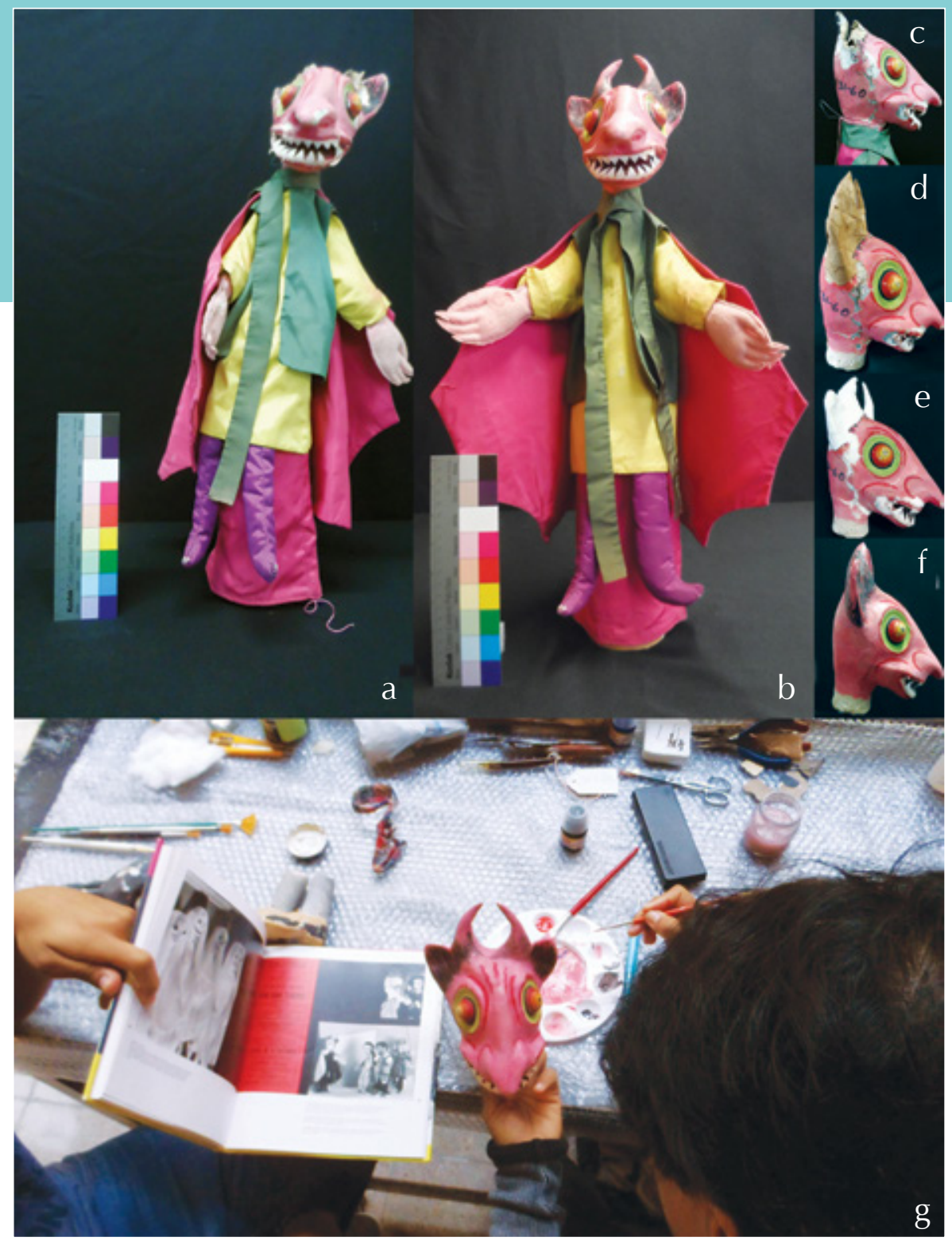

\section{Referencias}

\section{Cerdá, Enrique y Hugo Cerdá}

1966 Teatro de guiñol: historia, técnica y aplicaciones del teatro guiñol en la educación, Caracas, Ministerio de Educación.

Garduño Ortega, Ana

2010 "Los títeres de Rosete Aranda y su restaurador: Sergio A. Montero", Intervención, Revista Internacional de Conservación, Restauración y Museología 1: 39-44.

Giménez Cacho, Marisa y Francisca Miranda Silva

2010 Época de oro del teatro guiñol de Bellas Artes, México, Conaculta.
Giorguli Chávez, Liliana, Sergio Montero, Verónica Chacón, et al.

2014 Informe del Proyecto de Restauración de la Colección de la Época de Oro del Teatro Guiñol, documento mecanoescrito, México, Archivo ENCRYM-INAH.

Iglesias Cabrera, Sonia y Guillermo Murray Prisant

1995 Piel de papel, manos de palo: historia de los títeres en México, México, Espasa-Calpe Mexicana. INBA

2010 El teatro guiñol de Bellas Artes. Época de oro, México, INBA.

List Arzubide, Germán

1997 Comunicación personal con 


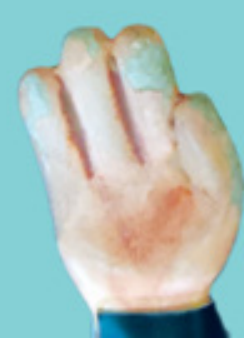

Sergio Arturo Montero Alarcón sobre el origen de la época de oro del teatro guiñol de Bellas Artes, México.

Mata Delgado, Ana Lizeth y Karen Landa Elorduy

2011 "La intervención del artista en la restauración de arte contemporáneo", Intervención, Revista Internacional de Conservación, Restauración y Museología 3: 74-79.
Miranda Silva, Francisca 2014 El arraigo del arte titeril en México, 1940-1960, México, Centro Nacional de Investigación, Documentación e Información Teatral "Rodolfo Usigli" (CITRU), INBA-SEP.

Montero Alarcón, Sergio Arturo

"La restauración de los títeres de Rosete Aranda", Imprimatura. Revista de Restauración 11: 3-6.
Sáizar, Consuelo

2010 “Presentación”, en Giménez Cacho y Miranda Silva, Época de oro del teatro guiñol de Bellas Artes, México, Conaculta, 1-2

UNAM

1997 Germán List Arzubide. Teatro guiñol (ilustración de Ramón Alva de la Canal), México, Difusión CulturalUNAM.

\section{Síntesis curricular del/os autor/es}

\section{Sergio Arturo Montero Alarcón}

Escuela Nacional de Conservación, Restauración y Museografía (ENCRyM), Instituto Nacional de Antropología e Historia (INAH), México smontero37@yahoo.com.mx

Profesor de la Escuela Nacional de Conservación, Restauración y Museografía (ENCRYM), Instituto Nacional de Antropología e Historia (INAH), México, durante más de 50 años. Uno de los fundadores de la restauración como disciplina profesional en nuestro país, respecto de la cual realizó estudios de pintura mural en la antigua Checoslovaquia. Entre sus restauraciones destacan la de la Estela 1 de Bonampak, Chiapas; la de la escultura de adobe crudo de El Zapotal, Oaxaca; la de los murales del Polyforum Cultural Siqueiros, Distrito Federal, y la de la Colección de Títeres de Rosete Aranda (todos ellos, en México). Fue galardonado con el Premio al Mérito Titiritero por el Museo Nacional del Títere (Munati), Huamantla, Tlaxcala (México) y el Gobierno del Estado de Tlaxcala (México). Coordinador del Proyecto de Restauración de los Murales de La Moreña, La Barca, Jalisco (México), en 1972 y de 2007 a 2012. En 2014 fue director general del Proyecto de Restauración de la Colección de la Época de Oro del Teatro Guiñol de Bellas Artes (ENCRyM-INAH, México).

\author{
Verónica Chacón Roa \\ Sistema de Transporte Colectivo Metro (STC-Metro), México \\ veroxchacon@yahoo.com.mx
}

Egresada de la licenciatura en restauración (Escuela Nacional de Conservación, Restauración y Museografía [ENCRyM], Instituto Nacional de Antropología e Historia [INAH], México), con una trayectoria profesional de 25 años, durante los cuales ha colaborado en diferentes instituciones y proyectos entre los que destacan la coordinación de la conservación-restauración de las pinturas de caballete de los retablos de la Misión de San Javier, Baja California Sur (México), a cargo de la Coordinación Nacional de Conservación del Patrimonio Cultural (CNCPCINAH), en 1997, así como la restauración del telón del Teatro Juárez (Instituto de la Cultura de Guanajuato) en 2005, ambos en México. Desde hace 15 años trabaja en el Sistema de Transporte Colectivo Metro (STC-Metro), México y como tal ha coordinado los proyectos de conservación de la Pirámide de Ehécatl (2002-2015); la elaboración de base de datos con avalúos de los bienes culturales del STC-Metro (2007), proyecto galardonado con el tercer lugar en el Premio Nacional en el Colegio de Valuadores de ese año; y la restauración del mural del maestro Rafael Cauduro en la estación Insurgentes Línea 1, en colaboración con el Seminario-Taller de Conservación de Obra Moderna de la ENCRyM-INAH (México) en 2011. En 2014 fue coordinadora residente del Proyecto de Restauración de la Colección de la Época de Oro del Teatro Guiñol de Bellas Artes (ENCRyM-INAH, México). 